\title{
Level of Compliance with the Risk Reduction and Disaster Preparedness Program among Public Secondary Schools in Buenavista, Bohol, Philippines
}

\author{
ALVEN A. LOPEZ \\ http://orcid.org/0000-0002-5865-3480 \\ ven_alvz89@yahoo.com.ph \\ NILDA A. ECHAVEZ \\ http://orcid.org/0000-0002-6607-5190 \\ naechavez@universityofbohol.edu.ph \\ JEROME C. MAGALLEN \\ http://orcid.org/0000-0002-8793-0897 \\ jmmagallen@universityofbohol.edu.ph

\section{ELIJAH L. SALES} \\ http://orcid.org/0000-0002-7248-4230 \\ elsales@universityofbohol.edu.ph
}

\section{ABSTRACT}

Risk reduction is recognized as vital for building a more equitable future and for reducing the severity of losses during disasters. Effective risk reduction occurs when there is cooperation between sectors of society, and there is an existing disaster preparedness program in place. The primary thrust of this study was to determine the level of compliance with the school risk reduction and disaster preparedness program among the public secondary schools in the District of Buenavista, Bohol, Philippines. It sought to determine compliance in the aspects of safe learning facilities, school disaster management and disaster risk reduction 
in education. The study employed quantitative method through a survey questionnaire anchored on the instruments developed by the Department of Education (DepEd). The findings revealed that schools had a good compliance level on disaster preparedness. However, some problems were encountered such as inadequate training materials and lack of training among the school disaster risk reduction management teams. Despite these challenges, both teachers and students agreed that the public secondary schools were generally compliant. A need was seen to continue the conduct of disaster preparedness training and seminars as well as budget allocation to finance the publication and dissemination of training materials of the program for distribution to schools.

Keywords: Risk reduction, disaster preparedness, disaster management, education, secondary schools, Buenavista, Bohol, Philippines

\section{INTRODUCTION}

The world at present is experiencing increased exposure to risks and hazards of both climate-related and human-made disasters that pose a threat to lives and sustainable development efforts. This scenario needs serious attention so disaster capacity and mitigation efforts can be formulated to reduce population exposure and vulnerability in international and local settings. Disasters are inevitable, but their scope and magnitude are often magnified due to unsustainable development that has not taken into account the possible hazard impacts in a particular location. The effects of such can be minimized if the population has a better understanding of locally-experienced hazards and implements corresponding preventive or mitigating measures.

A report from the Asian Disaster Reduction Center (2002) states that Asia has been suffering from about 38 percent of the major natural disasters of the world. The Asian region accounts for 57 percent of people killed and 88 percent of the people affected by natural disasters. Southeast Asia is exposed to all types of hazards and has been coping with their effects for hundreds of years. In its Annual Disaster Statistical Review for 2012, the Centre for Research on the Epidemiology of Disasters ranked the Philippines third worldwide in terms of the number of reported natural disaster events and first in the 
number of disaster-related mortalities in 2011. The Philippines' archipelagic makeup and geographic location make it most vulnerable to disasters and hazards, both natural and human-made. This was manifested in the destruction caused by the super typhoon Yolanda (Haiyan) which devastated the islands of Leyte, Samar and other Visayan islands that even well-built schools and other educational buildings suffered serious damage, with their roofs being blown away and windows shattered (Esteban, Valenzuela, Yun, Mikami, Shibayama, Matsumaru, \& Nakamura, 2015).

The disasters experienced in the Philippines spurred the DepEd (Department of Education) authorities to integrate the disaster risk reduction and management in their curricula. Section 14 of Republic Act 10121 (or the Philippine Disaster Risk Reduction and Management Act of 2010) requires the DepEd among other agencies to integrate the said curricula. For the elementary and junior high school levels, DRRM (Disaster Risk Reduction and Management) education has not been made a stand-alone subject but only a component of subjects such as science, technology, and social science. The DepEd, however, has made DRRM education as an independent subject for the senior high school level. In Central Visayas, a devastating earthquake hit Bohol which disrupted education throughout the region. The damage to education infrastructure was extensive (Bohol Earthquake Action Plan, 2013). Multiple schools were rendered unusable because of damage or prolonged use as shelters.

As cited by Benson (2016), such disasters have caused many developing countries significant financing gaps in the event of a disaster; falling back instead on the reallocation of planned capital and recurrent spending to meet more immediate post-disaster spending requirements and often redirecting capital budgets over a number of subsequent years to meet reconstruction costs.

Shaw, Kobayashi \& Kobayashi (2004) maintain that education and awareness inoculates a "culture of disaster preparedness" in students and empowers them to make the right decisions should they encounter such situations in the future. Muttarak and Pothisiri (2014) found that formal education can increase an individual's preparedness for disasters and thus reduce vulnerability to natural hazards.

However, a conducted by Tuladhar, Yatabe, Dahal, \& Bhandary (2015) found that some of the teachers do not have enough knowledge about disaster and risk reduction issues in the educational sector. Thus, it was 
recommended that DRRM education is promoted to communities through well-groomed school teachers to reduce disaster risks and to establish a disaster-prepared society which correlates with Bandura's (1986) social cognitive theory. It is said that people become motivated to respond to disasters when they form their basis on outcome expectancies and selfefficacy so they must be oriented on the consequences of disasters.

A study of Sinha, Pal, Kasar, Tiwari, \& Sharma (2008) recommends that students must be exposed to different orientations, workshops and mock drills and similar practical exercises which are helpful in developing the interest of the learners as well as improving knowledge and awareness. The study conducted by Rambau, Beukes, \& Fraser (2012) recognized the role of education for encouraging the integration of disaster risk education in school curricula in countries vulnerable to natural hazards and the safe construction and renovation of school buildings to withstand natural hazards. Thus, Skinner (2014) stressed the importance of educating the students through positive reinforcement such as disaster stimulation exercises and drills were more effective than punishment when trying to change and establish behaviors. This leads individuals to learn and be aware of different risks about disaster issues.

Furthermore, an important factor in ensuring the sustainability of disaster resilience and preparedness approaches lies in the ownership and use of national and local government institutions (Parsons, Glavac, Hastings, Marshall, McGregor, McNeill, Morley, Reeve, \& Stayner, 2015). This manifests how the decision maker sets alternatives in light of their possible consequences as explained by Hansson (2005) in his decision theory. He posits that local authorities have a big role for the safety and security of the students since they are persons with closer contact to the people of the community. Such institutions found in the community will be guided especially in the education sector where the students are among those vulnerable to the effects of any disaster.

All these discussions spurred the researchers to conduct this study to explore the level of compliance with the risk reduction and disaster preparedness program among the public secondary schools in Buenavista District, Province of Bohol. The researchers hope that the findings of this study can form the basis of an action plan to enhance or improve school risk reduction and disaster preparedness. 


\section{RESEARCH METHODOLOGY}

The study aimed to determine the level of compliance with the risk reduction and disaster program of the DepEd among the public secondary schools in Buenavista District, Division of Bohol for the school year 20172018.

Furthermore, it aimed to delve deeper into the following aspects:

a.) The level of compliance with the school risk reduction and disaster preparedness program as perceived by the respondents in the aspects of safe learning facilities, school disaster management and disaster risk reduction in education.

b.) The problems encountered by the teachers in the implementation of the school risk reduction and disaster preparedness program

The research investigation employed a quantitative method employing survey questionnaire to 512 respondents which comprised of teachers and senior high school students. This was distributed to 64 teachers and 350 students from Cangawa National High School; 11 teachers and ten students from Lubang National High School; and 16 teachers and 61 students from Panghagban High School. All schools are located in Buenavista, Bohol, Philippines.

The said questionnaire was anchored on the instrument formulated by the DepEd in its School Disaster Risk Reduction and Management Manual (2012) with four-point Likert scale. There were 41 questions which were divided into three categories namely: safe learning facilities (17), school disaster management (10); and disaster risk reduction in education (14). The questionnaires were given to the senior high school students and secondary school teachers. There were also additional modified questions that will be only answered by the teachers which comprise financial aspect (5), technical aspect (5) and human aspect (7) to determine the problems encountered on the implementation of school risk reduction and disaster preparedness.

Such parameters for the level of compliance on school risk reduction and disaster preparedness program were as follows: 3.26 - 4.00 mean highly complied, $2.51-3.25$ means moderately complied, $1.76-2.50$ means slightly complied and $1.00-1.75$ means not complied. While for problems encountered by the teachers on the school risk reduction and disaster preparedness program, the parameters are as follows: $3.26-4.00$ 
means highly encountered, $2.51-3.25$ means moderately encountered, $1.76-2.50$ means slightly encountered and $1.00-1.75$ means not encountered.

In the preparation for the gathering of data, an approval to conduct the study was secured from the Office of Vice-President for Academics of the University of Bohol. Then, the study underwent an ethics review by the Ethics Review Committee of the said university. Approval was then sought from the Schools Division Superintendent of DepEd - Division of Bohol. Upon approval by the Superintendent, the letter was shown to principals/ school heads informing them of the approval of the said undertaking. After which, a letter of consent/agreement was sent to the parents of the senior high school students who have an age of 17 and below. After the approval of the parents, an assent letter was sent to each of the respondents, teachers and the students, for the legal distribution of the questionnaires. The data gathered was analyzed and interpreted through analysis of variance (ANOVA) test to determine the significant degree of variance, the Scheffe's test to further test the significant variance to where the difference lies, and $\mathrm{T}$-Test of Correlated Means to get the significant degree of difference.

\section{RESULTS AND DISCUSSION}

Anchored on the results of this study, the findings are summarized as follows.

Result on the level of compliance with the school risk reduction and disaster preparedness program as perceived by teachers.

It revealed an overall mean of 3.20 at the parameter of "moderately complied" which means that their schools have moderate compliance level in risk reduction and disaster preparedness. This was a manifestation of the DepEd Division Order 37, s. 2015 or The Comprehensive Disaster Risk Reduction and Management (DRRM) in Basic Education Framework that the authorities in the basic education sector have made inroads in their efforts towards resilience-building in offices and schools, and ensuring that quality education is continuously provided and prioritized even during disasters and emergencies..

Result on the level of compliance with the school risk reduction and disaster preparedness program as perceived by students.

It revealed an overall mean of 3.21 or "moderately complied" which suggested that the respondent students felt that their schools were generally compliant with the disaster risk reduction and management program cur- 
rently in place. Students considered their schools to be a safe and accessible learning environment generally free from hazards.

Result on the problems encountered in the implementation of school risk reduction and disaster preparedness as perceived by the teachers.

For the Financial Aspect, "limited resources (other than funds; such as training materials; space for training, etc.)" was ranked first with a mean of 3.07 or a "moderately encountered' problem. The DepEd has a repository of learning materials but no specific training materials for disaster risk reduction management. They just incorporated it into existing subjects, and they had minimal training materials for the teachers. The lack of learning and other materials continues to burden teachers and students alike so much so that even DepEd officials have bemoaned this shortage of materials besetting the country's public schools (Meinardus, 2003).

For the Technical Aspect, "no handbook/guidelines about the preparations' with a mean of 2.70 or a "moderately encountered" problem ranked first. The problem with disaster preparedness handbook/guidelines in educational sector was still a challenge as identified in the Toolkit for Building Disaster-Resilient School Communities in South East Asia (2014). It was confirmed that the reproduction of more resource materials like modules for mainstreaming of DRRM in schools and Education School Facilities Manuals and Disaster Risk Reduction Resource Manual to schools for school heads and school staff has remained a challenge for the Department of Education.

For the Human Aspect, "lack of training among members of the faculty" ranked highest with 2.81 or a "moderately encountered" problem. The study of Borromeo, Babila, Orbon, Paez, Estapon, \& Gayoba (2017) confirms that this same issue plagues other educational institutions in the country. This is also confirmed in the report by the Commission on Audit (2016) which stated that there were inadequately trained and equipped response teams. The role of DRRM programs in school is to provide enough knowledge and information to teachers. Due to the lack of interest and knowledge in the subject, teachers often feel reluctant to give priority to disaster-related topics of curriculum and most of the time; this was not taught to the students in their academic sessions. 


\section{CONCLUSION}

Anchored on the preceding findings, the following conclusions were drawn:

Both teachers and students agree that the said public secondary schools have generally been compliant with the risk reduction and disaster preparedness program.

The schools encountered financial, technical and human problems during the implementation of the Risk Reduction and Disaster Preparedness program to wit:

- Financially, the schools were generally not hampered by lack of budgetary allocation for the said programs. However, they were hindered by limited resources such as specific training materials and suitable venues to conduct related training.

- Technically, the schools had to deal with the recurring issue of the DepEd having no disaster preparedness handbook or guideline(s) in place that was easily available for dissemination to school personnel.

- Personnel-wise, the schools were hamstrung by the lack of risk reduction and disaster preparedness training among the members of the faculty or those designated to be members of the schools' response team to disasters and calamities.

\section{RECOMMENDATIONS}

To maximize the effectiveness of this study, the researchers recommend that the following measures be implemented:

1. The DepEd - Bohol Division must continue to conduct risk reduction and disaster preparedness related seminars and training or workshops for all teachers and students at least once a year to optimize their knowledge and skills in disaster-related matters. Experts in disaster preparedness should be invited as focal persons or resource speakers to orient students and teachers.

2. The division must allocate and ensure that there are sufficient funds to finance the printing of training materials and the construction of venues for risk reduction and disaster preparedness training. Handbooks or guidelines related to disaster preparedness should also be provided to each school as resource materials are very 
important tools in helping teachers and students better understand hazards and thus, school communities can cope better during times of disasters.

3. Teachers must create linkages or connection with the local government unit or non-governmental organizations to maximize available resources found within the community for disaster-related activities.

4. Individual schools should continue to prioritize the disaster-related activities in their priority improvement areas as included in their School Improvement Plan.

\section{REFERENCES CITED}

Asian Disaster Reduction Center (2002). ADRC 20th Century Asian Natural Disasters Data Book. Retrieved from https://goo.gl/H18EkU, (accessed last 17 September 2018).

Bandura, A. (1986). Social foundations of thought and action: A social cognitive theory. Englewood Cliffs, NJ, US: Prentice-Hall, Inc.

Benson, C. (2016). Promoting Sustainable Development through Disaster risk management. Metro Manila, Philippines. Asian Development Bank. Retrieved from: https://goo.gl/4AmtqJ, (accessed last 25 September 2017).

Borromeo, Robert A., Babila, Jolly S., Orbon, Myrtle, Paez, Winifredo C., Estapon, Natividad D., Gayoba, Arlene M. (2017). Determining the Disaster Preparedness of Students and Non-teaching Employees of Adventist University of the Philippines (AUP) and Its Financial implications. Retrieved from https://goo.gl/DoWfLj, (accessed last 3 October 2017).

Commission on Audit (2016, February 1) Consolidated Report on the Audit of the Disaster Risk Reduction Management (DRRM) Fund for the year ended December 31, 2014. Retrieved from https://goo.gl/NmC7gE, (accessed last 27 September 2017). 
Department of Education. (2012). School Disaster Risk reduction and Management Manual. Pasig, Metro Manila: Disaster Risk Reduction and Management Service. Retrieved from https://goo.gl/VDfH5Z, (accessed last 9 October 2017).

Esteban, M., Valenzuela, V. P., Yun, N. Y., Mikami, T., Shibayama, T., Matsumaru, R., ... \& Nakamura, R. (2015). Typhoon Haiyan 2013 evacuation preparations and awareness. International Journal of Sustainable Future for Human Security, 3(1), 37-45. Retrieved from https://goo.gl/99kkDn, (accessed last 19 September 2017).

Hansson, S. O. (2005). Decision theory: A brief introduction. Stockholm, Sweden. Department of Philosophy and the History of Technology Royal Institute of Technology (KTH). Retrieved from https://goo.gl/ nZftYp, (accessed last 30 September 2017).

Humanitarian Response (2013, October 25). Bohol Earthquake Action Plan. Retrieved from https://goo.gl/aK4Mqi, (accessed last 8 October 2017).

Medina, A. (2016). Promoting a culture of disaster preparedness. Journal of business continuity \& emergency planning, 9(3), 281-290. Retrieved from https://goo.gl/zTxeF5, (accessed last 8 October 2017).

Meinardus, R. (2003). The crisis of public education in the Philippines. Business World Internet Edition. Retrieved from https://goo.gl/NmFm64, (accessed last 17 October 2017).

Muttarak, Raya and Pothisiri, Wiraporn. (2013). The Role of Education on Disaster Preparedness: Case Study of 2012 Indian Ocean Earthquakes on Thailand's Andaman Coast. Ecology \& Society, 18 (4). pp. 1-16. Retrieved from https://goo.gl/JxQ9Ac, (accessed last 30 September 2017).

Parsons, M., Glavac, S., Hastings, P., Marshall, G., McGregor, J., McNeill, J., Morley, P., Reeve, I., \& Stayner, R. (2016). Top-down assessment of disaster resilience: a conceptual framework using coping and adaptive capacities. International Journal of Disaster Risk Reduction, 19, 1-11. 
Retrieved from https://goo.gl/EYo6eS, (accessed last 21 September 2017).

Rambau, T. S., Beukes, L. D., \& Fraser, W. (2012). Disaster Risk Reduction through school learners' awareness and preparedness. Jàmbá: Journal of Disaster Risk Studies, 4(1), 1-11. Retrieved from https://goo.gl/ ATZ2oG, (accessed last 27 September 2017).

SEAMEO INNOTECH. (2014). Toolkit for Building Disaster-Resilient School Communities in Southeast Asia. Retrieved from https://goo.gl/un9LBM, (accessed last 18 September 2017).

Shaw, R., Shiwaku Hirohide Kobayashi, K., \& Kobayashi, M. (2004). Linking experience, education, perception and earthquake preparedness. Disaster Prevention and Management: An International Journal, 13(1), 39-49. Retrieved from https://goo.gl/zYPnMa, (accessed last 2 October 2017).

Sinha, A., Pal, D. K., Kasar, P. K., Tiwari, R., \& Sharma, A. (2008). Knowledge, attitude and practice of disaster preparedness and mitigation among medical students. Disaster Prevention and Management: An International Journal, 17(4), 503-507. Retrieved from https://goo.gl/ nD6q5B, (accessed last 1 October 2017).

Skinner, B. F. (2014). Contingencies of reinforcement: A theoretical analysis (Vol. 3). BF Skinner Foundation. Retrieved from https://goo. gl/3RfctC, (accessed last 29 September 2017.)

Tuladhar, G., Yatabe, R., Dahal, R. K., \& Bhandary, N. P. (2015). Assessment of disaster risk reduction knowledge of school teachers in Nepal. International Journal of Health System and Disaster Management, 3(1), 20. Retrieved from https://goo.gl/mg998C, (accessed last 6 September 2017). 